\title{
Clinical testing of implanted pacemakers
}

\author{
EDGAR SOWTON ${ }^{1}$ and KENNETH GRAY \\ Institute of Cardiology, 35 Wimpole Street, London W1M 8EX
}

The function of implanted pacemakers was assessed at a special pacemaker clinic at intervals of three to six months. Measurements of the basic discharge rate of the pacemaker were made and the waveform was recovered from skin electrodes and displayed on an oscilloscope screen. The impulse was photographed from the screen and subsequent waveform analysis was carried out. Reproducible results were obtained for measurements of peak amplitude and impulse duration provided unipolar electrodes were in use and the patients were studied in the same position.

The range of variation of the measurements during the lifetime of different models of normally functioning pacemakers is given. Test measurements taken before failing pacemakers were removed have been correlated with the subsequently established cause of failure and the waveform analysis test has been shown to be clinically reliable. The value of the test depended largely upon the type of pacemaker but it correlated well with rate changes in pacemakers designed to slow as battery exhaustion developed.

The clinical value of waveform analysis tests is in the diagnosis of exit block, electrode failure, and premature battery exhaustion and in determining the optimum time for pacemaker replacements. The indications for replacement of pacemakers at the National Heart Hospital are given. Initial experience with an automatic analyser with three types of pacemaker shows that rapid measurements of the waveform parameters can be achieved with accuracy.

Although there is continuing improvement in the reliability of cardiac pacemakers, there is a need for methods of evaluation of implanted systems by simple external measurements. Specific techniques and apparatus have been developed for use with General Electric pacemakers (Preston, Judge, Bowers, and Morris, 1966) and Vitatron pacemakers (Thalen, van den Berg, Homan ven der Heide, and Nieveen, 1969) but these cannot be universally applied. More general approaches to the problem have been the mapping of the field along the electrode wires, vector studies of the stimulating impulse (Dekker, Büller, and Schuilenburg, 1965; Castellanos, Lemberg, Salhanick, and Berkovits, 1968; Green, Forbes, Bain, Shaw, and Kenmure, 1969), and analysis of the impulse as detected by induction or from skin electrodes. This technique was first described by Davies and Sowton in 1964 and clinical reports are now available from several centres (Knuckey, McDonald, and Sloman, 1965; Sowton, 1967; van den Berg, Rodrigo, Thalen, and Koops, 1967; Davies and Sowton, 1964). In this report we present data obtained by this method from patients attending the pacemaker clinic at the National Heart Hos-

1Correspondence to Dr. Edgar Sowton, Cardiac Dept., Guy's Hospital, London S.E.1 pital, London. The results have been restricted to those obtained since 1 January, 1967, because of changes in pacemaker design, and are based on observations on approximately 200 patients.

\section{PATIENTS}

All patients were followed in a pacemaker clinic where they were first seen soon after discharge from hospital and at subsequent intervals of three to six months. Patients were also seen if they reported any untoward symptoms or if they were referred by their doctor for urgent checking.

A full 12-lead electrocardiogram (ECG) was taken at the initial visit and a long strip of one standard lead was recorded at every attendance for the detection of stimuli which failed to produce ventricular contraction. The basic discharge rate of the pacemaker was counted or obtained from the ECG ; the paper transport speed of the ECG machine was frequently checked to avoid errors. In non-competitive pacemakers (i.e., atrial-triggered, ventriculartriggered, or ventricular-inhibited demand models) it was established that detection of spontaneous cardiac activity was satisfactory and that the pacemaker would pace the heart if necessary. This sometimes involved slowing the heart by carotid sinus pressure or by intravenous injection of up to $10 \mathrm{mg}$ edrophonium chloride (Tensilon). Some pacemakers in- 
corporated a reed switch activated by an external magnet which temporarily converted the unit into a simple fixed-rate asynchronous pacemaker. The additional tests detailed in the present paper were applied to these non-competitive pacemakers as if they were simple fixed-rate units. The stimuli produced by the triggered pacemakers we used were identical whether they paced the ventricle or were triggered by an $\mathbf{R}$ wave to fall during the absolute refractory period. Investigation of pacemaker function was then carried out.

\section{METHODS}

On an ordinary ECG the pacemaker stimulus appears only as a single vertical line but if this is displayed on an oscilloscope with a fast time base, the appearance is similar to that of the output pulse of the pacemaker and characteristics such as amplitude and pulse duration can easily be measured. The waveform is very similar to the current waveform of the pacemaker output.

The patient is positioned supine on a couch with head and trunk raised $45^{\circ}$ and standard ECG electrodes are attached to the limbs. The appropriate leads (e.g., left arm and right arm) are then connected to the vertical input terminals of a Tektronix type 502A oscilloscope. Proper synchronization, sweep, and voltage settings result in a repetitive picture of the stimulus artefact which is then photographed with a Polaroid camera. It is standard practice for the vertical axis to show the amplitude in millivolts of the stimulus as detected from skin electrodes and the horizontal axis to show the time. Typical sensitivity settings are $20 \mathrm{mV} / \mathrm{cm}$ (y axis) and $0.5 \mathrm{msec} / \mathrm{cm}(\mathrm{x}$ axis). The impulse deflection may be positive or negative, depending upon the relative positions of the pacemaker stimulating and indifferent electrodes in the thorax and also upon the choice of ECG lead displayed on the oscilloscope. The ECG lead chosen for impulse waveform analysis is that with the largest stimulus deflection and subsequent results are obtained with the same ECG lead, even when this no longer shows the largest deflection. Measurements are taken also from other leads when large changes in? amplitude are noted so that the stimulus vector canfs be plotted.

ANALYSIS Each type of pacemaker produces a charact్ teristic impulse picture which is then analysed forpeak amplitude and impulse duration. In patients with certain types of pacemaker the ratio of the amplitude $0.5 \mathrm{msec}$ from the start of the impulse to the initialo peak amplitude was used to indicate the time constant of the heart-electrode-output circuit complex and is referred to as the 'decay ratio' (Sowton, 1967). Thisos measurement applies only to the 'differentiated' wave forms such as those produced by Elema Schonander $\vec{A}$ or Biotronik pacemakers and is not applicable to 'current limited' pacemakers such as Cordis or Devices models (Fig. 1). The Polaroid photographand results of waveform analysis are presented on as form for storage in the patient's notes (Fig. 2).

When the electronic testing had been completed $\stackrel{\widehat{S}}{S}$ each patient was seen by a doctor who had the results available. At this stage clinical examination could be carried out, any radiographs or pathological tests ordered, and drug therapy reassessed.

The interpretation of clinical tests depends upon as knowledge of the expected changes of each type of pacemaker as battery exhaustion approaches. These are summarized for several types of apparatus in Table I.

REPRODUCIBILITY OF MEASUREMENTS In order to 3 assess the reliability of the impulse analysis, measure-? ments were taken by the above method on 12 patientso with unipolar systems. The ECG electrodes were removed and the patients were allowed to walk around. The electrodes were then replaced at differento sites on the same limbs (e.g., below the knee instead: of above) and the impulse photographs were repeated. The whole process was again carried out for a third time. Provided the patient reassumed the same posi- $\frac{0}{3}$
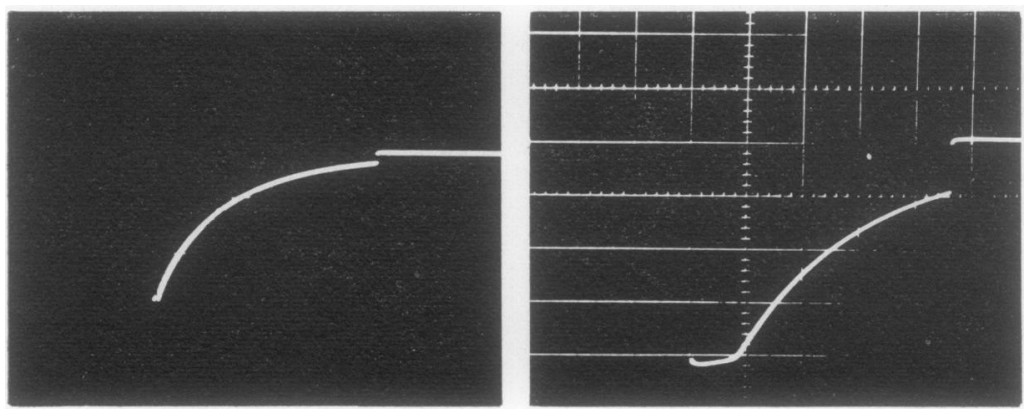

FIG. 1. Photographs of pacemaker impulses detected from skin electrodes and displayed on an oscilloscope screen: (left) differentiated waveform (Elema Schonander EM153) lead II; (right) current limited waveform (Cordis Ventricor)lead $I$. 
PACEMAKER CLINIC

NAME: MR M. M.

DATE: 28.1 .69

HISTORY: DEVICES FIXED RATE PACEMAKER (75/MIN) IMPLANTED

9 MONTHS. ENDOCARDIAL LEAD

DRUGS: NONE

MEDICAL EXAMINATION RATE: 74/MIN B.P. $135 / 65$

NO SIGNS OF CONGESTIVE HEART FAILURE. LUNGS

CLEAR LIVER NOT PALPABLE

E.C.G: MOSTLY.FIXED RATE PACING COMPETITION AFTER EXERCISE

X-RAY:

VECTOR

MEASUREMENTS

\begin{tabular}{|c|c|c|c|}
\hline & PEAK & 0.5 M.SECS & DECAY \\
\hline 1 & $-94 m V$ & $-66 m V$ & $80 \%$ \\
\hline II & $-80 \mathrm{mV}$ & $-54 m V$ & $67.5 \%$ \\
\hline III & & & \\
\hline
\end{tabular}

PULSE WIDTH $1.35 \mathrm{msec}$

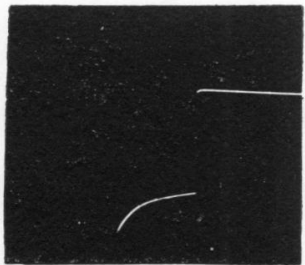

LEAD I $y=20 \mathrm{mV} / \mathrm{cm}$

$x=0.5 \mathrm{msec} / \mathrm{cm}$

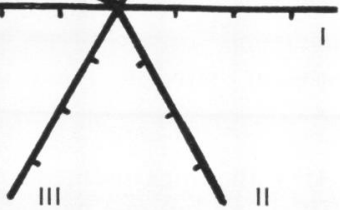

9 Months $-156^{\circ}$

- $110 \mathrm{mV}$

At Implantation - $156^{\circ}$

$-110 \mathrm{mV}$

CONCL. ELECTRICAL MEASUREMENTS:

NORMAL FUNCTION

REMARKS:

SEE IN 4 MONTHS

FIG. 2. National Heart Hospital pacemaker clinic data sheet. The Polaroid photograph taken from the oscilloscope screen (lower left) shows a normal waveform for this pacemaker. In this and all subsequent impulse photographs the y axis indicates amplitude in millivolts and the $x$ axis time in milliseconds. 
T A B LE I

CHANGES WITH BATTERY EXHAUSTION

\begin{tabular}{|c|c|c|c|c|c|}
\hline Manufacturer & Model & Earliest Change & $\begin{array}{l}\text { Manufacturer's } \\
\text { Estimate of } \\
\text { Approximate } \\
\text { Time Available } \\
\text { for Replacement } \\
\text { of Pacemaker }\end{array}$ & Basic Rate & $\begin{array}{l}\text { Impulse } \\
\text { Duration }\end{array}$ \\
\hline \multicolumn{6}{|l|}{ Biotronik } \\
\hline Fixed rate & IP45 & Slows & About 2 months & Slows & Little change \\
\hline Ventricular triggered & IRP44 & Slows & About 2 months & Slows & Little change \\
\hline $\begin{array}{l}\text { Ventricular inhibited } \\
\text { Atrial triggered }\end{array}$ & $\begin{array}{l}\text { IDP44 } \\
\text { IVP54 }\end{array}$ & $\begin{array}{l}\text { Slows } \\
\text { Slows }\end{array}$ & $\begin{array}{l}\text { About } 2 \text { months } \\
\text { About } 2 \text { months }\end{array}$ & $\begin{array}{l}\text { Slows } \\
\text { Slows }\end{array}$ & $\begin{array}{l}\text { Little change } \\
\text { Little change }\end{array}$ \\
\hline \multicolumn{6}{|l|}{ Cordis } \\
\hline Fixed rate & Ventricor & Slows & 1-2 months & Slows & Little change \\
\hline Ventricular triggered & Ectocor & $\begin{array}{l}\text { Slows and later fails to sense } R \\
\text { waves }\end{array}$ & 1 month & $\begin{array}{l}\text { Slows (129B on- } \\
\text { wards) }\end{array}$ & Little change \\
\hline $\begin{array}{l}\text { Atrial triggered } \\
\text { Devices }\end{array}$ & \multicolumn{2}{|r|}{ 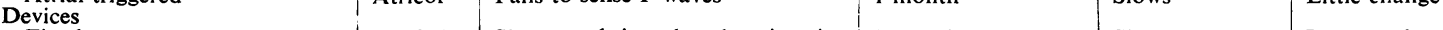 } & 1 month & Slows & Little change \\
\hline Fixed rate & TF2970 & Slows and impulse duration in- & 3 months & Slows & Increases by \\
\hline Demand (ventricular inhibited) & 2980 & $\begin{array}{l}\text { creases } \\
\text { Small increase in rate or } 20 \% \text { re- } \\
\text { duction in rate }\end{array}$ & 2 months & $\begin{array}{l}\text { Increases to } \\
\max \text { of } 97 / \\
\min \end{array}$ & $\begin{array}{l}\text { to } 100 \% \\
\text { Increases }\end{array}$ \\
\hline \multicolumn{6}{|l|}{ Elema Schonander } \\
\hline Fixed rate & EM150 & Rate decreases approx. $10 / \mathrm{min}$ & - & Little change & Increases \\
\hline Fixed rate & EM152B & Rate decreases approx. $10 / \mathrm{min}$ & - & Little change & Increases \\
\hline Ventricular triggered & EM153 & $\begin{array}{l}\text { Triggering threshold increases } \\
\text { Loss of synchronization }\end{array}$ & - & Little change & Increases \\
\hline Atrial triggered & EM155 & $\begin{array}{l}\text { Impulse duration increases } 0.5 \mathrm{msec} \\
\text { Triggering threshold increases } \\
\text { Loss of synchronization } \\
\text { Impulse duration increases } 0.5 \mathrm{msec}\end{array}$ & $\ldots$ & Little change & Increases \\
\hline \multicolumn{6}{|c|}{ 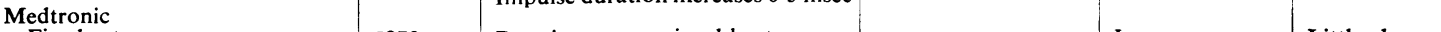 } \\
\hline Demand (ventricular inhibited) & $\begin{array}{l}5841 \\
5842 / 3\end{array}$ & $\begin{array}{l}\text { Rate increases } \\
\text { Loss of one beat, rate the same } \\
\text { Loss of second cell, rate decreases }\end{array}$ & - & $\begin{array}{l}\text { Increases } \\
\text { Decreases }\end{array}$ & $\begin{array}{l}\text { Little change } \\
\text { Little change }\end{array}$ \\
\hline \multicolumn{6}{|c|}{ 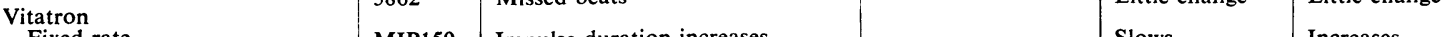 } \\
\hline Fixed rate & MIP150 & Impulse duration increases & - & Slows & Increases \\
\hline Fixed rate (with threshold) & MIP500T & $\begin{array}{l}\text { Impulse duration increases } \\
\text { Impulse amplitude decreases } \\
\text { Change in relative threshold }\end{array}$ & $\begin{array}{c}\text { Change within } 2-4 \\
\text { weeks when rela- } \\
\text { tive threshold falls }\end{array}$ & Slows & Increases \\
\hline Demand (ventricular inhibited) & MIP400R & Fails to sense & $10 \%$ & Slows & Increases \\
\hline
\end{tabular}

tion (reclining at $45^{\circ}$ ) the measurements were reproducible within $95 \%$ in all but one patient in whom they were within $92 \%$. Different positions (sitting and lying down) resulted in changes of up to $30 \%$. During quiet respiration there was no noticeable change in amplitude within the respiratory cycle provided the patient was reclining at $45^{\circ}$.

In 10 patients the effect of moving the site of the implanted pacemaker by gentle manual pressure was investigated. The maximum alteration in peak voltage produced by this manœuvre was $64 \%$ and the mean change in the 10 patients was $23 \%$. In all cases the values returned to control readings when the pacemaker was allowed to return to its original position. Spontaneous migration of an implanted pacemaker is rare after the first few weeks but it is apparent that this would account for changes in peak voltage. The phenomenon is detected clinically because the stimulus vector alters in orientation but not in magnitude and can be confirmed by $x$-ray.

The amplitude of the stimulus measurement was considerably larger with unipolar systems (Cordis, Devices, Elema) than with bipolar (Medtronic) and we do not feel that satisfactory amplitude measurements can be obtained with this method for bipolar pacing. The impulse duration, however, can be्త measured accurately with both types and so we have continued to include waveform photographs in oug follow-up procedures for patients with bipola electrodes.

\section{RESULTS}

Typical waveform pictures for pacemakers witt 'differentiated' or 'capacitor discharge' outputsand for those with 'current-limiting' outputs arô shown (Fig. 1). The most striking difference in waveforms is that the initial portion of the wave form is modified in current-limited pacemakers s $\delta^{\mathrm{J}}$ that a 'plateau' appears. The duration of this plateau depends upon the total resistance of the load (i.e., electrodes plus heart plus return througe tissues) and an increase in the plateau duration suggests a fall in resistance; this is unusual in practice. Small reductions in plateau duration ma occur over the first three months following attachment of electrodes to the heart and are probably due to the development of local fibrosis with a resulting increase in resistance. Larg8 

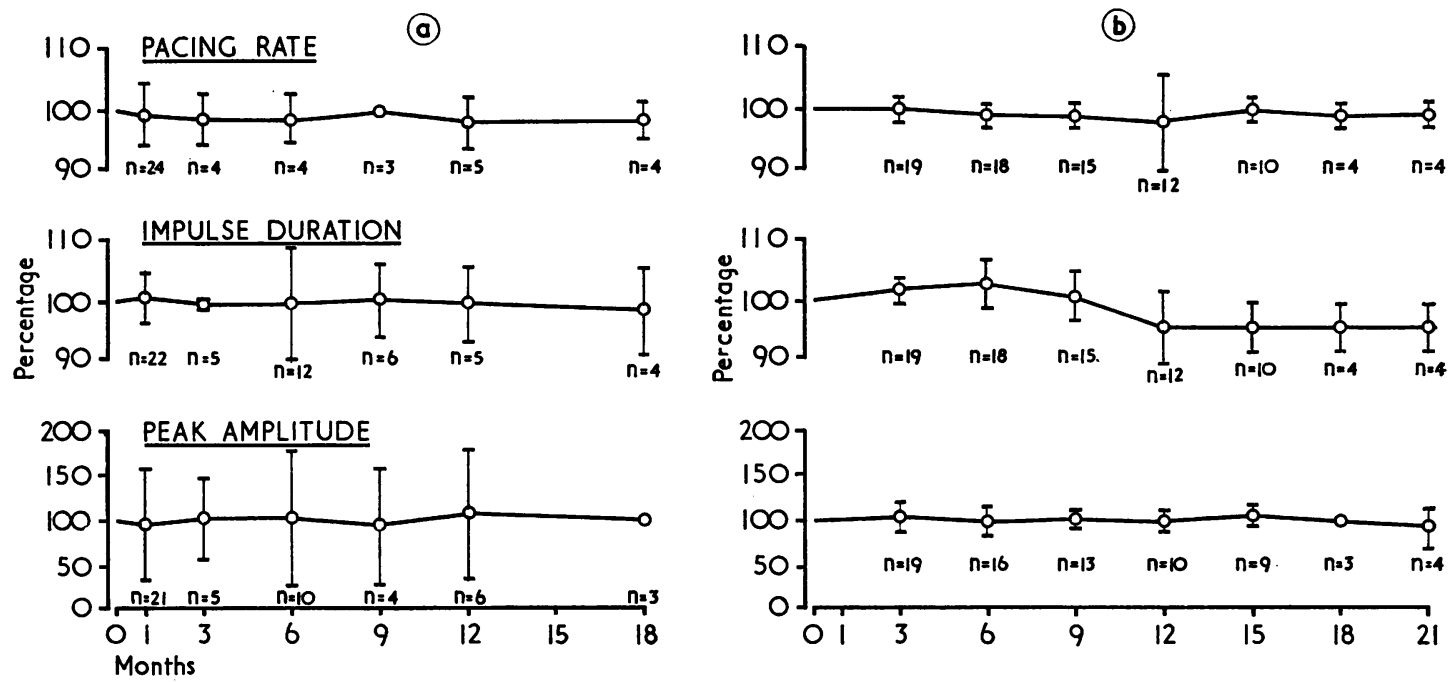

FIG. 3. Variation in waveform with normal functioning pacemakers. Mean figures and two standard deviations are indicated. The variation in amplitude is very much larger with bipolar electrodes than with the unipolar: (a) Medtronic Demand pacemaker model 5841 ; (b) Cordis Ventricor fixed-rate pacemaker.

changes in either direction suggest a fault in the electrode wire in its insulation or at the point of attachment to the pacemaker. This finding has been used clinically by us and also by Grendahl (1969).

One particular fault is the penetration of tissue fluid into the electrode/pacemaker junction with the consequent development of an alternative pathway for the electrical impulse to follow to reach the positive indifferent electrode which is usually attached to the side of the pacemaker. Pacing of the heart may continue and there is usually no change in rate so that diagnosis of the fault depends to a large extent upon waveform analysis. A helpful additional finding is twitching of skeletal muscle around the pacemaker which was not originally present: this twitching may be provoked or stopped by pressure over the electrode connexion.

The variation from control values compatible with normal function was investigated by analysing the changes in impulse duration, peak (i.e., initial) amplitude of the stimulus, and the discharge frequency or standby rate of pacemakers which were continuing to function normally after being implanted for one year (Fig. 3). The control values were those obtained one month after pacemaker implantation. Our normal range is defined as two standard deviations from the control values and for all models a change in basic rate of $7 \%$ (approximately equivalent to 5 beats $/ \mathrm{min}$ ) is out- side this range. Similarly, a change in impulse duration of $10 \%$ strongly suggests that the pacemaker is abnormal as does an alteration of $25 \%$ in the amplitude of the unipolar stimulus detected from skin electrodes.

T A B L E I I

'NORMAL LIMITS' OF VARIATION FROM INITIAL GRAD-

\begin{tabular}{|c|c|c|c|}
\hline Type of Pacemaker & $\begin{array}{c}\text { Rate } \\
\text { (beats/min) }\end{array}$ & $\underset{\substack{\text { Impulse } \\
\text { Duration }}}{ }$ & $\begin{array}{c}\text { Stimulus } \\
\text { Amplitude } \\
\%\end{array}$ \\
\hline $\begin{array}{l}\text { Cordis Ventricor } \\
\text { Cordis Ectocor }\end{array}$ & \multirow{2}{*}{$\begin{array}{c}5 \\
5 \\
\text { (basic rate) } \\
5 \\
5 \\
\text { (basic rate) }\end{array}$} & $\begin{array}{l}10 \\
15\end{array}$ & $\begin{array}{l}20 \\
25\end{array}$ \\
\hline $\begin{array}{l}\text { Devices T.F. } 2970 \\
\text { Medtronic } 5841 \text { demand }\end{array}$ & & $\begin{array}{l}15 \\
10\end{array}$ & $\begin{array}{c}20 \\
75 \\
\text { (bipolar } \\
\text { electrode) }\end{array}$ \\
\hline
\end{tabular}

The different models of pacemaker did not behave identically. Table II shows a list of 'normal values' for the different pacemakers and it is suggested that any pacemaker which gives figures outside these limits should be closely followed. In general it is our practice to replace any unit showing a change in basic rate (i.e., standby rate of non-competitive models or fixed rate of other models) exceeding 5 beats $/ \mathrm{min}$ and any unit which is nearing the end of its expected life and which shows a marked change in waveform. Borderline changes in waveform in a pacemaker unit which is not nearing the end of its expected 
life are regarded as an indication for closer followup.

DECAY RATIO Decay is defined as the ratio of amplitude at $0.5 \mathrm{msec}$ after onset of the pulse to the peak amplitude. The decay ratio is related to the actual time constant (an electronic term indicating the time for the amplitude to fall to $37 \%$ of its initial value) of the pacemaker/electrode/heart circuit but it is considerably easier to measure clinically. A time constant of this type is not applicable to pacemakers with a capacitor discharge output with current limiting (i.e., Cordis, Devices) or varying output characteristics (Medtronic). Our own experience is that $95 \%$ of normal pacemakers have decay ratios which have not changed by more than $20 \%$ from the control at any time.

FAILURES It is apparent that by far the greatest proportion of test data on failed pacemakers must be related to models which are no longer available. Our experience with 34 pacemakers removed between 1 January, 1967, and 31 March, 1969, and subsequently confirmed to be faulty is shown (Table III). These figures do not include pace-

T A B L E I I I

34 FAULTY PACEMAKERS (1 JANUARY, 1967, to 31 MARCH, 1969)

\begin{tabular}{l|cc}
\hline & No. \\
\hline Rate change alone & 6 & $18 \%$ \\
Impulse waveform change alone & 10 & $29 \%$ \\
Changes in both rate and waveform & 18 & $53 \%$ \\
\hline Total & 34 & $100 \%$ \\
\hline
\end{tabular}

makers changed electively nor those removed for causes such as exit block, infection, or electrode malplacement in which the pacemaker was normal. Of these 34 units, $28(82 \%)$ had abnormal impulse analysis tests and $24(71 \%)$ had a change in rate exceeding 5 beats/minute. If the only test had been a change in discharge rate these 24 faulty pacemakers would have been detected but the remaining $29 \%$ would have been passed as normal at the time of testing.

Most, but not all, models of pacemaker now commercially available include circuitry to ensure that the discharge rate slows as the battery voltage falls. Analysis of a further 15 Cordis pacemakers (Ventricor and Ectocor) removed for battery failure between 1 April, 1969, and 31 March, 1970, showed a rate change exceeding 5 beats/min in 14 cases. The other patient presented at the pacemaker clinic because of an erratic pulse and her
Ectocor was found not to be sensing spontaneous QRS complexes consistently. Waveform analysis confirmed reduction in peak voltage. We therefore $\overline{\bar{\omega}}$ regard rate changes as the most important test $\widehat{\Phi}$ measurement and waveform analysis as confirmatory evidence although we have noted on several ${ }^{\infty}$ occasions that abnormal waveform results precede $\vec{O}$ changes in rate.

Failure of the pacemaker system occurred in $\vec{\omega}$ 17 patients in whom Devices Abdominal pace- $\stackrel{2}{\overrightarrow{2}}$ makers were implanted and in whom at least one set of measurements had been taken just before $O$ failure. Of these 17 patients, seven $(41 \%)$ had ab- $N$ normal impulse analysis results without a signifi- $\overrightarrow{\mathrm{c}}$ cant change in rate ( 5 beats $/ \mathrm{min}$ or more). A rate 0 change alone with a normal impulse analysis was found in only one case and a combination of ab- $\bar{z}$ normal impulse pictures, pacing rate, and intermittent failure of ventricular capture on the ECG $\stackrel{\rho}{\supset}$ was present in the remainder. Eleven of the $17 \vec{\varphi}$ patients $(65 \%)$ had abnormal impulse pictures alone or in combination with other abnormalities.

EXIT BLOCK In seven patients treated since 1 s January, 1967, pacing threshold rose to above the capabilities of the pacemaker, representing an in- $\stackrel{0}{\circ}$ cidence of $3.5 \%$. In each case the diagnosis was $\stackrel{\mathbb{Q}}{\mathscr{2}}$ greatly strengthened by the finding that all test $\overrightarrow{\vec{B}}$ results were unchanged. This proved to be one of $\frac{}{3}$ the most useful applications to the test procedures and we feel a diagnosis of exit block should not? be made without the demonstration that pacemaker function remains normal. Grendahl (1969)음 reports similar experiences. Alternative diagnoses, $\underset{\sim}{\stackrel{0}{x}}$ which must be considered when all tests remain 0 normal but pacing ceases, include perforation of 3 . the heart or displacement of a transvenous elec- 8 trode.

ELECTRODE FAILURE Partial fracture of an elec- 을 trode is usually accompanied by a fault in the $\frac{7}{0}$ insulation and a characteristic waveform change (Fig. 4). Typically there is a reduction in ampli- $\sim$ tude with a change to a more differentiated wave- $N$ form (i.e., one with a steeper initial fall-off) soN that the decay ratio increases. The appearance of ${ }_{\sigma}^{\omega}$ additional 'spikes' at the beginning and end of each impulse (Fig. 4) also raises the suspicion of faulty insulation although we have noted the development of these 'spikes' in patients whose ${ }_{T}^{+}$ pacemakers continued to function normally for ${ }^{-}$ many months and we consider them as an indica- $-\vec{\Phi}$ tion to follow the patient more closely but not to $\frac{\mathbb{\mathbb { N }}}{\mathrm{O}}$ change the pacing system.

The duration of the plateau with current limited pacemakers (Fig. 2) may provide informa-8̊ 


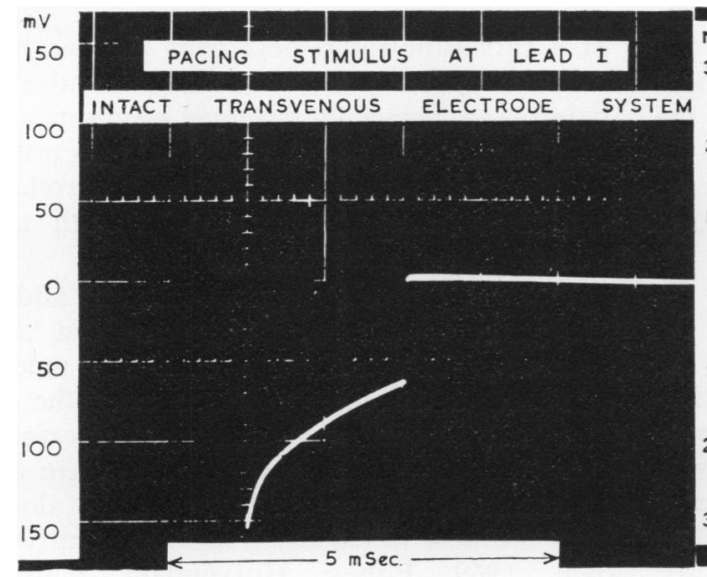

(a)

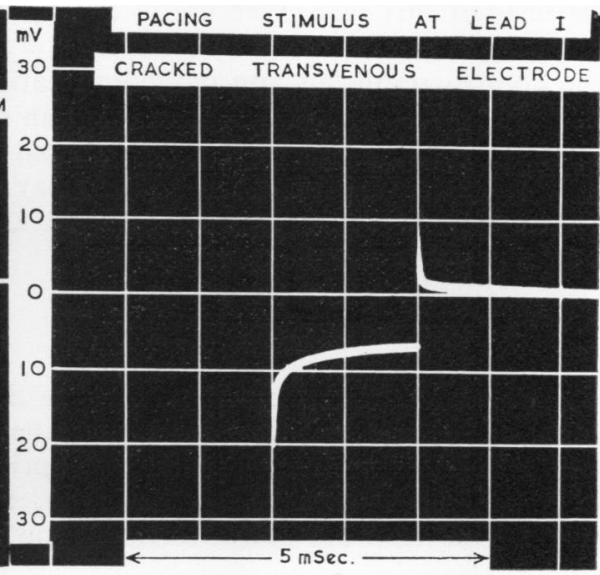

(i)

FIG. 4. (a) The impulse waveform with a normal electrode. (b) The typical change in waveform with a fractured electrode in which electrical contact is maintained but the insulation is faulty. Note the 'spikes' at the beginning and end of the impulse, the reduced amplitude, and the alteration in curvature of the waveform. The vertical scale is not the same for the two pictures.

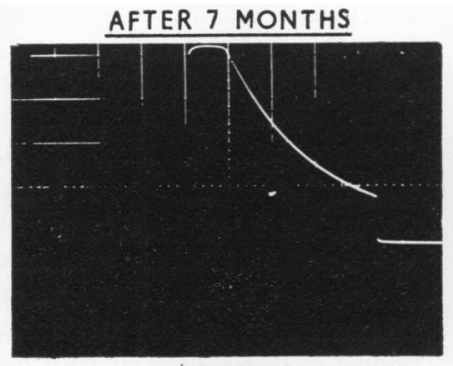

LEAD III

(a)

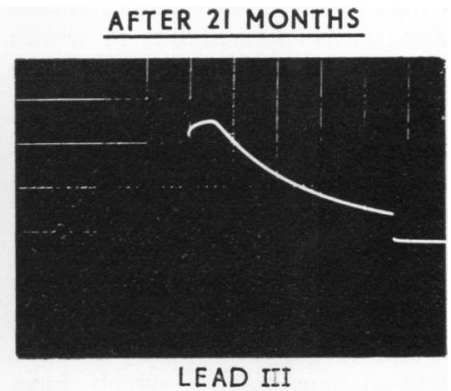

(b)

FIG. 5. Waveform changes due to battery depletion in a Cordis fixed rate pacemaker. Pacing was continuing with a basic rate of $70 / \mathrm{min}$ control at implantation $72 / \mathrm{min}$ ). At 21 months the main change is a reduction in amplitude compared with that found after seven months. The ratio of pacemaker output voltage to limb lead stimulus amplitude was subsequently shown to be the same at the time of implantation $(4.9 \mathrm{~V} / 220 \mathrm{~m} \mathrm{~V})$ and at the time of removal $(2.7 \mathrm{~V} / 125 \mathrm{~m} \mathrm{~V})$.

tion about the electrode. Large changes in plateau duration, particularly occurring several weeks after implantation, raise the suspicion of wire fracture with intact insulation or of a high resistance joint, typically between the pacemaker and the electrode.

BATTERY EXHAUSTION The main change in waveform as the battery ran down was a reduction in amplitude (Fig. 5a). Minor variations from this pattern were seen when one cell became prematurely exhausted and depended upon the final impedance of the faulty cell.
COMPONENT FAILURE A wide variety of changes was noted when pacemaker components failed. A change in impulse duration was highly suspicious in this respect and was often accompanied by alterations in decay ratio and amplitude and usually (but not always) in discharge rate (Fig. $5 b)$.

CLINICAL USE OF TESTS In all 10 cases where a functioning pacemaker was removed solely on the basis of abnormal impulse analysis tests (Table III), a fault was subsequently discovered in the pacemaker. These results suggest that waveform 
analysis tests of this type offer useful clinical information.

If the control results in any individual patient differ appreciably from those anticipated from the normal range (Table I) an explanation should be sought. If none can be found the patient may be allowed to continue pacing but should be kept under closer supervision than usual.

\section{DISCUSSION}

A policy of pacemaker follow-up testing, as described here, is time-consuming for both patients and hospital and is justified only if appropriate benefits can be demonstrated. Our experience suggests that the tests are useful in the following circumstances:

1. In exit block they provide evidence that the fault is not in the pacemaker or electrodes.

2 . In the diagnosis of pacing faults it may be possible to identify the method and site of failure, particularly where insulation fractures are present.

3. The test results may draw attention to patients in whom pacing is apparently normal but in whom there is an installation fault such as a high resistance connexion between electrode and pacemaker.

4. Routine testing of all patients detects some pacemakers which are likely to fail in the near future.

5. When patients present with stable pacing but a history suggestive of intermittent failure to pace, the tests may detect a faulty but functioning pacemaker.

6. Routine testing towards the end of the expected pacemaker lifetime enables the maximum period of service to be obtained and avoids unnecessary elective replacement of individual pacemakers which have considerable potential remaining. In many patients we have obtained six months' normal service beyond the manufacturer's recommended time for elective change and on occasions the pacemakers have functioned for over a year beyond this time.

7. A policy of follow-up testing is useful in establishing the expected lifetime of new models of pacemaker.

Analysis of the pacemaker stimulus detected from skin electrodes is both reliable and reproducible for unipolar systems. When pacemaker batteries fail there are changes in many aspects of the tests but, in general, battery depletion resulted in a peak decreased amplitude. This finding supports our earlier observations (Sowton, 1967) and confirms those of Knuckey et al. (1965) for early Devices units, of Keller (1969) for Cordis pacemakers, of van den Berg et al. (1967) for Vitatron pacemakers, and of Ryden (1969) for Elema pacemakers.

The most widely used follow-up test is the fixed-rate discharge rate of pacemakers and this can often be checked daily by the patient. The use of a transistor radio held over the pacemaker too detect signals emitted with each impulse may be음 helpful, and specially designed monitors are avail- $\frac{\bar{p}}{-}$ able for this purpose. Impulse analysis testing pro- $\mathbb{\Phi}$ vides additional information and correlates wellp with rate changes, alteration in both tests fre- quently being produced together.

The test procedures are simple and add little to $\overrightarrow{\vec{\omega}}$ the patient's follow-up visit provided the sames electrodes and cable are used for reading the $\vec{x}$ standard ECG and for detection of the impulse. N They can be accurately and rapidly performed by a trained technician and the results are available $\vec{A}$ at once. Pacemaker clinics organized along thesecr lines are now in existence in many centres (Gren-으 dahl, 1969; Edhag, Hofvendahl, Karlof, and Morgensen, 1970 ; Furman, Escher, Parker, and 3 Solomon, 1969; Irnich and Effert, 1970) and experience supports our conclusions that patient super- $\supset$ vision in this way provides additional safety $\overrightarrow{0}$ against pacemaker failure and is an aid to rapid correction of pacemaker faults should they develop (Davies and Siddons, 1969; Parsonnet, Myers, \& Gilbert, and Zucker, 1970). The information obtainable is still limited but the methods are applicable to all pacemakers.

Our experience has been similar to that of $\stackrel{\varrho}{\vec{A}}$ Parsonnet et al. (1970) who showed that followup tests of this type reduced the frequency of emergency pacemaker replacements to about onefifth of the level found in non-clinic patients. Escher found that a policy of routine testing of implanted pacemakers reduced the emergency admission rate $\underset{\times}{\stackrel{D}{\mathcal{D}}}$ at Montefiore Hospital, New York, from $61 \%$ to $28 \%$ with almost complete abolition of true pace- 3 . maker 'crises' (Escher, D. J., personal communication). Edhag et al. (1970) report that oscilloscope analysis of waveform pictures has proven of diag-은 nostic value in all 43 patients whose pacemakers? were removed for premature failure over a two- o year period at Serafimer Hospital, Stockholm. In 17 cases the only evidence of abnormality was a $O$ change in the waveform analysis figures. Sixteen $N$ of these 17 pacemakers were subsequently proven $\underset{\mathrm{W}}{\mathrm{N}}$ to be faulty; the remaining pacemaker was removed because of incorrect calibration of the waveform picture. Similar benefits have been 0 reported from other European centres (Emmrich $\stackrel{\Phi}{+}$ and Kraft, 1968; Paeprer, Schaldach, Liebenschütz, and Thormann, 1968). No method of testing pace- $\bar{O}$ makers can be expected to prevent all sudden $\mathbb{\mathbb { D }}$ failures, particularly if these are due to abrupt $\frac{?}{\mathbb{D}}$ component failure. Fortunately this is now very $\frac{\varrho}{0}$ rare. 
At the present time our indications for replacement of implanted pacemakers are as follows:

1. Electrocardiographic proof of failure of a pacing stimulus falling outside the refractory period to drive the heart.

If high threshold exit block is diagnosed shortly after implantation, the patient is initially managed with oral prednisone and temporarily paced with an external synchronized pacemaker (Sowton and Barr, 1970).

2. A clear history or ECG evidence of failure of pacing; for example, a return of Adams-Stokes syncopal attacks.

3. Late development of sensing failure (after three months) so that non-competitive pacemakers fail to respond to spontaneous beats.

4. An alteration of $5 \mathrm{stimuli} / \mathrm{min}$ or more from the initial rate (standby rate for non-competitive pacemakers).

5. Progressive changes in waveform analysis figures; the maximum tolerable variation depends upon the type of pacemaker and electrode. Deviations $50 \%$ greater than those shown in Table II indicate replacement and lesser deviations add support if other tests are also abnormal.

6. Elective change is occasionally carried out when the pacemaker approaches or has passed the anticipated time of failure, particularly if, for example, the patient is going abroad.

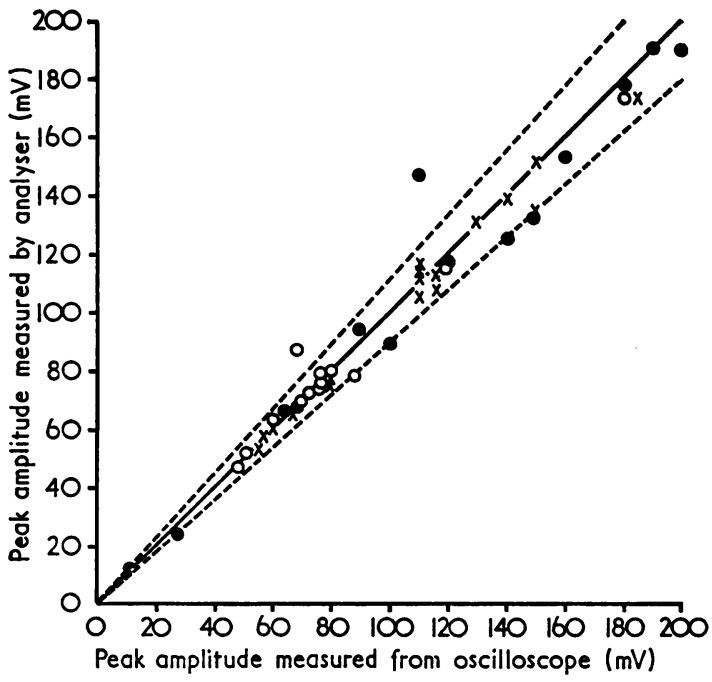

FIG. 6. Comparison of the peak amplitude of the pacing impulse detected from skin electrodes and measured with a Nukab pacemaker analyser and also from photographs on the oscilloscope screen: 41 of 43 comparisons fall within $\pm 10 \%$ of the identity line. = Devices demand $(n=13) ; \times$ Devices T.F. fixed rate $(n=17) ; \bigcirc$ Cordis Ectocor ( $n-13)$; - line of identity; - - 10\% variation from identity.
Ryden (1969) has recently shown an apparatus which automatically analyses the waveform of implanted capacitor-discharge pacemakers detected from skin electrodes. The rate, amplitude, impulse duration, and actual time-constant of the impulse (i.e., time for the initial amplitude to fall to $37 \%$ of its value) are digitally displayed on the screen. The equipment was developed for use with Elema pacemakers and its clinical place with other models is not yet established; a comparison of impulse amplitude measured with our standard technique and with this analyser is shown in Fig. 6. Our early experience over a 12-month period indicates that this type of automatic impulse analyser can be very valuable and similar apparatus is being developed elsewhere.

The ease with which impeding battery failure may be detected depends largely upon the circuitry design which manufacturers incorporate into their pacemaker units. A design which involves slowing of the basic discharge rate when the batteries become exhausted offers the simplest solution available at present. This method has the added advantage that the majority of patients are able to check the pacemaker themselves so that battery failure will be detected as early as possible.

Future developments will probably include some method for feed-back of information from implanted pacemakers, perhaps by the incorporation of a secondary coil so that signals can be transmitted and received by external apparatus in the manner at present available for General Electric and Vitatron pacemakers (van den Berg et al., 1967; Preston et al., 1966).

\section{REFERENCES}

Castellanos, A., Lemberg, L., Salhanick, L., and Berkovits B. V. (1968). Pacemaker vectorcardiography. Amer. Heart J., 75, 6.

Davies, J. G., and Siddons, H. (1969). The detection of impending failure in implanted pacemakers. Thorax, 24, 74.

and Sowton, G. E. (1964). Cardiac pacemakers. Phys. in Med. Biol., 9, 257.

Dekker, E., Büller, J., and Schuilenburg, R. M. (1965). Aids to electrical diagnosis of pacemaker failure. Amer. Heart J., 70, 739.

Edhag, O., Hofvendahl, S., Karlof, I., and Morgensen, L. (1970). External measurement of implanted pacemaker characteristics-a clinical appraisal. Brit. Heart J., In press.

Emmrich, K., and Kraft, D. (1968). Verlaufsbeobachtungen oszillographischer Impulsuntersuchungen bei implantierten Herzschrittmachern. Dtsch. Gesundh, -Wes., 23, 1063. 
Furman, S., Escher, D. J. W., Parker, B., and Solomon, N. (1969). Electronic analysis for pacemaker failure. Ann. thorac. Surg., 8, 57.

Green, G. D., Forbes, W., Bain, W. H., Shaw, G. B., and Kenmure, A. C. F. (1969). Detection of faults in implanted pacemakers. Brit. Heart J., 31, 707.

Grendahl, H. (1969). Registration of pacemaker-induced skin potentials in the routine control of implanted pacemakers. Scand. J. clin. Lab. Invest., 24, 251.

Irnich, W., and Effert, S. (1970). Kontrolle implantierter Schrittmacher. Dtsch. med. Wschr., 95, 1091.

Keller, W. (1969). Ventricor pulse parameters as a function of battery state. Technical Report. Cordis Corp. Miami. Aug. 28, 1969.

Knuckey, L., McDonald, R., and Sloman, G. (1965). A method of testing implanted cardiac pacemakers. Brit. Heart J., 27, 483.

Paeprer, H., Schaldach, M., Liebenschütz, H. W., and Thormann, I. (1968). Funktionsprüfung implantierten Herzschrittmacher. Wiederbeleb. u. Organersatz., 5, 85.
Parsonnet, V., Myers, G. H., Gilbert, L., and Zucker, I. R (1970). Prediction of impending pacemaker failure in $\overline{x O}$ pacemaker clinic. Amer. J. Cardiol., 25, 311.

Preston, T. A., Judge, R. D., Bowers, D. L., and Morris J. D. (1966). Measurement of pacemaker performance $\vec{\nabla}$ Amer. Heart J., 71, 92.

Ryden, L. (1969). A new device for detection of impending pacemaker failure. Panel discussion. Ann. N.Y. Acad Sci., 167, 816.

Sowton, E. (1967). Detection of impending pacemaker $\overrightarrow{-}$ failure. Israel J. med. Sci., 3, 260.

- and Barr, I. (1970). Emergency management of patients with missed pacing. Amer. Heart J., 79, 458.

Thalen, H. J., van den Berg, J. W., Homan van der Heide, N J. N., and Nieveen, J. (1969). The Artificial Cardiaciu Pacemaker. Royal Van Gorcum Ltd., Assen, TheNetherlands.

van den Berg, J., Rodrigo, F. A., Thalen, H. J. T., and Koops, J. (1967). Photo-analysis of the condition of implanted pacemakers and electrode circuits. Proc. kon. ned. Akad. Wet, Ser. C (Biol. med. Sci), 70, 419. 